\title{
Are International Students' Preferred Pedagogy Influenced by Their Educational Culture?
}

\author{
Junko Winch \\ Education School, University of Southampton \\ Highfield, Southampton SO17 1BJ, UK \\ E-mail: dr.junko.winch@gmail.com
}

Received: 07-02- 2015

Accepted: 18-03-2015

Published: 30-04-2015

doi:10.7575/aiac.ijels.v.3n.2p.1

URL: http://dx.doi.org/10.7575/aiac.ijels.v.3n.2p.1

\begin{abstract}
The increasing number of international students is studying at British universities. This study investigates multicultural students' preferences on teaching and learning which was conducted at a university in the South of England during $2009 / 2010$ academic year. In the literature review, the framework used in this study is explained. The study sample was 34 students who were studying Japanese as a non-credit module. Quantitative and qualitative data was collected using questionnaires. The results showed that some students' preferred pedagogy appeared to be altered and influenced by British educational culture regardless of students' previous educational culture. In addition, the sample participants' preferred pedagogy are identified into given categories based on the framework of the study. Those who are in the teaching profession are encouraged to take into consideration of the educational cultures and teaching and learning practices from non-Anglophone countries.
\end{abstract}

Keywords: culture, globalisation, higher education, Japanese language teaching, multicultural, power distance index (PDI), uncertainty avoidance index (UAI)

\section{Introduction}

\subsection{Context}

The UK is one of the countries that have a diverse ethnic population, which is one of the visible changes after gobalisation. Similarly, globalisation has also made visible changes in the higher education sector. There are no geographical restrictions for choosing university to study and international students can not only study at the universities native to their own country but also they can study at universities where the learning and teaching culture is different from their native country. More international students choose to study at British universities and Japanese classrooms are also under the influence of globalisation. There were a total of nine different cultures among 19 students in the pilot study.

According to the vision statement of the majority of British universities, British universities attract a large proportion of international students globally and try to meet the teaching and learning needs of international students. Multicultural learning environment has given impact to make changes in the British higher educational establishments, trying to accommodate international students' requirements.

\subsection{The issue under consideration}

University students are usually asked to evaluate their course and their lecturers including language teachers at the end of the term. These results are also checked by the lecturers' managers. Course evaluation has become part of lecturers' performance review in order to see if they were able to enhance students' learning experiences and generate students' learning interests and enthusiasm.

If a British lecturer teaches a class where the majority of students are British students, i.e., the teacher and students share the same educational culture, the teacher may be able to anticipate students' teaching and learning expectations and needs, accommodate them and obtain good results. However, if a British lecturer teaches a class where the majority of students are non-British international students, or a case of language teachers who do not share the same educational culture with any of the students, he/she may not be able to anticipate all international students' teaching and learning expectations and needs.

Language teachers usually teach using the preferred teaching approaches of the institution where they live and teach. For example, if language teachers teach a language at a British university in the UK, the language teachers may teach language using British pedagogy. This is a common strategy for language teachers who teach in a class where the majority of students are British students. Another less common but possible strategy for language teachers is to teach language using the language teachers' comfortable pedagogy which is native to their country. In the case of Japanese language teaching, for example, a native Japanese teacher teaches using Japanese pedagogy. However, teaching Japanese using Japanese pedagogy in a class where majority of students is British students may make British students 
give a culture shock at first. However, the current educational climate is more globalised and it is common to teach students from various parts of the world. In this learning environment, what is the most effective pedagogy for teaching in order to enhance students' learning experiences and generate students' learning interests and enthusiasm?

\subsection{Research questions}

Language teaching approaches are believed to be universally effective. However, some students' reaction to the Communicative Language Teaching (CLT) in the pilot study showed different responses to British students' reaction to the CLT. The initial hypothesis was that international students' previous educational culture may be the cause of the different reaction. The second hypothesis was that there may be culturally preferred pedagogy and language teaching approaches. Therefore, the aim of this study is to examine the multicultural students' preferred pedagogy and ascertain whether students' previous or present educational culture relates to students' preferred pedagogy.

\subsection{Study format}

The next section discusses the framework of the study, followed by the methodology, results before the discussions and conclusion.

\section{Theoretical framework and two teaching approaches}

\subsection{Theoretical framework}

Hofstede et al.'s (2010) cultural taxonomy is used to understand the characteristics of two language teaching approaches used in the study. Hofstede's model may be considered too 'essentialism' (Godwin-Jones, 2013, p. 3) and the use of Hofstede's cultural categorisation may be too stereotypical and simplified as the reality is more complex, and there are various types of people with various perspectives. However, GLOBE Cultural Taxonomy is still built on Hofsted's work (Lustig and Koester, 2010, p. 112) and this categorisation is relevant for the purpose of this study.

His categorisations of culture consist of five dimensions (power distance, individualism-collectivism, masculinityfemininity, uncertainty avoidance, and long-term-short-term). This study examines the uncertainty avoidance and power distance dimensions.

\subsubsection{Uncertainty avoidance}

Hofstede et al. defines uncertainty avoidance as 'the extent to which the members of a culture feel threatened by uncertain or unknown situations (Hofstede et al., 2010, p. 191). High uncertainty avoidance index (UAI) scoring nations try to avoid ambiguous situations whenever possible, whereas low UAI-scoring nations do not worry about unknown situations. According to Hofstede et al. (2010, p. 192), the UK is ranked in the $68-69^{\text {th }}$ place out of 76 countries, which means that the UK has a weak uncertainty avoidance culture. High UAI scoring nations includes Greece and Bulgaria while the UK, China, Indonesia and Malaysia are low UAI scoring nations (Hofstede et al., 2010, p. 192-194).

Some of the preferred pedagogy of strong uncertainty avoidance are 'teachers supposed to have all the answers, students comfortable in structured learning situations and concerned with the right answers, precision and punctuality come naturally, and fear of ambiguous situations and unfamiliar risks' (Table 6.3 in Hofstede et al., 2010, p. 208). To contrast, the same equivalents of weak uncertainty avoidance are 'Teachers may say "I don't know", students comfortable with open-ended learning situations and concerned with good discussion, precision and punctuality has to be learned, and comfortable in ambiguous situation and with unfamiliar risks' (Table 6.3 in Hofstede et al., 2010, p. 208).

\section{Creativity vs. control}

Creativity and control seem to correlate with each other. As control is lessened in teaching, learners' creativity increase. Preference for one correct answer, error elimination, and routinisation are pedagogy for the strong uncertainty avoidance culture. The fields of study of mathematics and sciences usually adopt the one correct answer system as a common practice all around the world. It might be possible to say that students and teachers studying mathematics are likely to share a strong uncertainty avoidance culture compared to students and teachers from other departments such as music and art. On the other hand, creativity and open-ended questions are pedagogy for the weak uncertainty avoidance culture. An emphasis on creativity in teaching and learning means freedom from control or routine.

\subsubsection{Power distance}

Power distance is defined as 'the extent to which the less powerful members of institutions and organisations within a country expect and accept that power is distributed unequally' (Hofstede et al., 2010, p. 61). A large power distance index (PDI) indicates that society accepts an unequal distribution of power. The UK is ranked in the $65-67^{\text {th }}$ place among 76 countries (Hofstede et al., 2010, p. 59), which means that the UK has a small power distance culture. High PDI scoring nations includes Korea, Malaysia, Greece and Arabic-speaking countries while the UK and Australia are low UAI scoring nations (Hofstede et al., 2010, p. 57-59). 'Many Asian societies are high PD culture, while many Western societies have low PD values' (Dimmock, 2000, p. 47).

Some of the preferred pedagogy for the large power distance culture are 'teacher should take all initiatives in class' 'Teachers are guru who transfer personal wisdom' and 'students give teachers respect even outside classes' (Table 3.3 in Hofstede et al., 2010, p. 72). To contrast, the same equivalent of small power distance culture are 'teachers expect initiatives from students in class' 'teachers are experts who transfer impersonal truths' and 'students treat teachers as equals' (Table 3.3 in Hofstede et al., 2010, p. 72). 


\subsection{Teacher centred vs. student-centred class}

A teacher-centred class is pedagogy of large power distance educational culture. Teacher centre class used in this study is defined as 'The teacher initiating all communication. Students in a class speak up only when invited to' (Hofstede et al., 2010, p. 69). The strength of a teacher-centred class is that it provides all students with the same educational opportunities for all. A potential weakness of a teacher-centred class is that learning requirements from individual students may be difficult to meet. On the other hand, a student-centred class is pedagogy of small power distance educational culture and usually refers a class where students are expected to take the initiative. The strength of a student-centred class is to make students more proactive in learning. A potential weakness of a student-centred class is that they may not meet the needs of students who prefer passive learning approaches. Some might learn better by teachers presenting all the necessary important learning points rather than active learning.

\subsection{Specific research question}

This study addresses the following research question:

Are students' preferred pedagogy influenced by their' previous educational culture?

The research question was investigated by questionnaires which provide quantitative and qualitative data.

\section{Method}

The study was conducted during the first semester of the 2009/2010 academic year at a university in the south of England using 34 students who were study Japanese as non-credit module.

\subsection{Participants}

The participants were a mixture of undergraduate students, postgraduate students and mature students who were studying Stage 1 Japanese (no previous knowledge of the language). There were 13 cultures among total of 34 students. The breakdown of the participants were: one Australian, eleven British, three British-Chinese, one British Indian, one Bulgarian, seven Chinese, one Egyptian, two Greek, one Hong Kong-Chinese, one Indonesian, one Korean, three Malaysian-Chinese, and one New Zealand Chinese.

This research paid attention to any subtle cultural influences on individual student. For example, a student who was born and educated in the UK and has Chinese parents who were raised in China, and students who were born and educated in China have quite different cultural influences. Heritage was defined as being parentage or parental culture, and nationality was defined as the country where students were brought up. For this reason, they needed to be categorised separately and specific action was taken to take account of students whose culture had been influenced by more than two countries. Therefore, separate entries were created for British-Chinese, British-Indian, Hong KongChinese, and New Zealand-Chinese students.

Table 1 shows that there are more science major undergraduate students than non-science major students. Its ratio of undergraduate students' science and non-science is 14:6. In this sample population, more than half of the students (16 out of 34) study or work in science related study.

Table 1. Students' major

\begin{tabular}{lll}
\hline & Major & Number \\
\hline Mature students & & 8 \\
Undergraduate students & Economics and Management science & 1 \\
& Psychology & 2 \\
& Ship Science & 1 \\
& Mathematics & 8 \\
& Film & 1 \\
& Pharmacology & 1 \\
& Computer & 1 \\
& Mechanical Engineering & 1 \\
& Music & 1 \\
& Management Science and Accounting & 1 \\
& Medicine & 2 \\
MA students & HR management & 2 \\
PhD student & Fashion Management & 1 \\
Senior Research Fellow & Medicine & 1 \\
\hline
\end{tabular}




\subsection{Instruments - Two questionnaires}

Two questionnaires were used: the researcher questionnaire and the university course evaluation form. The researcher questionnaire was constructed specifically to investigate uncertain avoidance and power distance dimensions. The format of the questionnaires mostly consisted of closed questions with some open-ended questions. Both uncertainty avoidance and power distance dimensions had nine statements to determine students' preferred pedagogy and students were asked to tick the boxes for the answers most relevant to them. Students had the option to write their opinion in the open-ended questions. University course evaluation form consisted of seven open-ended questions and one closed question which was quantitative ratings of the unit and the tutor.

\subsection{Analysis of the questionnaires}

The students were grouped by ethnicity and they were compared in each group in depth. This enabled the examination of which end of the spectrum students' preferred pedagogy is based on this study's framework.

\section{Results}

\subsection{Uncertainty avoidance}

The Mainland-Chinese students adopt both a strong and weak uncertainty avoidance culture. The Mainland-Chinese students did not tick 'teachers supposed to have all the answers', which indicates their preference for weak uncertainty avoidance.

The British-Chinese student did not tick 'right answers' and 'teachers supposed to have all the answer' which indicates that she prefers the weak uncertainty avoidance culture. Another British-Chinese student was a medical student and he showed mixed preferences for strong ('right answers' and 'structured learning') and weak ('broad assignments', 'teacher may say 'I don't know' and 'good discussion') uncertainty avoidance.

Both strong and weak uncertainty avoidance exists from nine British students: one student who did not tick 'right answer' studies music as her major and the other student who ticked 'right answer' studies computing as his major. These different views could be influenced by their major whether science/engineering or humanities.

Malaysian-Chinese students might have a preference for strong uncertainty avoidance culture as they ticked 'teachers supposed to have all the answer' and did not tick 'teacher may say "I don't know"'. They also preferred the 'right answers' and their major was mathematics. However, according to Hofstede et al.'s uncertainty avoidance index (UAI), Malaysia is actually a weak uncertainty avoidance country. Perhaps the fact that both students major in mathematics could relate to this result as mathematics adopts one correct answer, which relates to strong uncertainty avoidance.

The Bulgarian student preferred strong uncertainty avoidance as he chose 'teachers supposed to have all the answers' and did not tick 'teacher may say "I don't know". However, he might be influenced by teaching and learning in an engineering environment.

A Korean student only ticked two boxes ('teacher supposed to have all the answers' and 'detailed assignments'), which indicate a preference for strong uncertainty avoidance.

An Egyptian student, a medical student, ticked most of the strong uncertainty avoidance boxes except 'broad assignment'.

A Greek PhD Medical student ticked exactly the same boxes as the British-Chinese undergraduate student whose major was medicine. She seemed to have a mixture of strong ('right answers' and 'structured learning') and weak uncertainty avoidance ('broad assignments', 'teacher may say 'I don't know' and 'good discussion'). She also made comment on the repetitive grammar exercise (which is preferred pedagogy for the strong uncertainty avoidance) in the textbook as follows: 'doing EXACTLY the same as in the example provided is not provided I think'.

An Australian student did not indicate a preference for either broad or detailed assignments, however, a mixture of strong ('structured learning' and 'right answers') and weak ('good discussion' and teacher may say 'I don't know') uncertainty avoidance was indicated.

\subsection{Power distance}

Mainland-Chinese students show a preference for a mixture of large and small power distance educational culture. They ticked 'teachers are experts who transfer impersonal truth' and 'teacher and student are equal relationship', which indicates a small power distance; however, they also ticked 'teacher should be treated with respect' and 'I will respect some teachers all my life even when I get old and my knowledge exceeds my teacher's', which shows a large power distance. However, one Mainland-Chinese student ticked 'a teacher's knowledge can be exceeded by that of a student one day, and there is no respect to the teacher when this happens'. This answer was an unexpected considering that Chinese speaking countries share a system of seniority and ticking this box contradicted this value. Perhaps her perception might have been influenced by the British educational culture after studying in the UK for four years. The international students' preference in teaching and learning may be subject to change and influenced by the British educational culture.

Two British-Chinese students ticked the statement 'teachers are treated with respect' and their reasons to tick this box were 'simple respect for others in general' and their 'ability'. The majority of reasons why 'teachers are treated with respect' were 'ability' and 'knowledge', while the others answered that it was common sense and that respect was given to people as good manners: 'everyone deserves respect when they are speaking and giving opinions'; 'should respect everyone equally'. 
There are mixtures of large and small power distance culture among British students. Five out of seven British students ticked 'there is an element of dependency from students to teacher', which is the characteristic of a large power distance. However, six out of seven British students ticked 'teachers are experts who transfer impersonal truth', which is the characteristic of a small power distance. One British student ticked the statement 'teachers are treated with respect' because of 'age and experience in life', which shows large power distance. Other British student answered that 'teachers are treated with respect' for 'ability', which shows preference for small power distance culture.

The pedagogy 'students should take initiatives in class' is the only value shared with two British students, which were not ticked by neither Mainland-Chinese nor British-Chinese students.

The British-Chinese students' preference mirrored those ticked by British students rather than those of MainlandChinese students. British-Chinese students and Mainland-Chinese students agreed on two values: 'teacher should be treated with respect' and 'teacher and student are equal relationship'. On the other hand, British-Chinese students and British students agreed on four values: 'teachers are gurus who transfer personal wisdom'; 'teacher should be treated with respect'; 'there is an element of dependency from students to teacher'; and 'teacher and student are equal relationship'. This suggests that British-Chinese student's educational culture is closer to that of British students than that of Mainland-Chinese students.

Two Malaysian-Chinese students ticked 'teachers transfer truths' and 'teacher and student are same', which indicates their preference for a weak uncertainty avoidance culture.

The Bulgarian student ticked 'teachers expect initiatives from students in class', which shows his preference for a small power distance educational culture.

The Korean student preferred student-centered classes, which shows that she preferred small power distant culture. It was expected that she would prefer a large power distance culture due to the system of seniority in Korea. This may be an indication of an individualist educational cultural influence, as she was studying at a British University for her MA degree. This was considered as another case which the international students' preference in teaching and learning might be subjected to change and influenced by the British educational culture.

The Egyptian student ticked 'teachers are treated with respect because they care enough about their subject to teach it'.

A Greek student ticked the box 'teachers are expected to take all initiatives in classes. This indicates that she preferred a large power distance culture. In addition, she gave a quantitative rating of 2 out of 5 in the university evaluation rating.

The Australian student expressed that 'teachers are treated with respect' because of 'ability'.

\section{Discussions}

As mentioned earlier, the research question asked whether students' preferred pedagogy is influenced by their previous educational culture. The results of the study indicated that the students did not seem to have specific preferences in uncertainty avoidance and power distance dimensions. Instead, they showed preference for the mixture of both end of the uncertainty avoidance and power distance dimensions. This result can be interpreted as follows: Firstly, it could be interpreted that preferences for both end of the uncertainty avoidance and power distance exist regardless of their educational culture. In other words, there are always different preferences for teaching approaches exist in any culture; Secondly, it could be assumed that university students who appeared to establish their preferences of teaching and learning did not have particular learning preference after all. In other words, they did not have particular preference for language teaching approaches.

There is one similarity in the preference between the Chinese heritage students and the British students in both dimensions. It is possible to say that Chinese heritage students teaching and learning preferences were more likely influenced by the British educational culture where they have received education. The learning preferences appeared to be influenced and conformed to the British educational culture, as Jin and Cortazzi (2006) claim that 'a framework of cultural expectations about learning will probably be modified or supplemented in relation to the expectation of teachers and students in the host culture' (p. 9).

The findings also showed that students who study science as their major might be influenced by the one correct answer logic, which was shown by the preference especially for the strong uncertainty avoidance culture. This implies that there could be other factors which might not seem to relate to culture which affect the preference for teaching approaches.

Some international students' preferred pedagogy was not reflected by their previous educational culture, where one would have anticipated otherwise. Since the multicultural learning environment provides place where students from two opposing cultures (in uncertainty avoidance and power distance dimensions), encounter numerous opportunities to choose the different pedagogy on the mix and match basis, alter and replace the educational values, which could be opposite from their own. If students find the experience successful and enhanced their learning, they may change their preferences.

To summarise, we need to consider the following three points with regards to sample students' preferred pedagogy within this study: i) the students' prior educational culture in which they received their previous education, ii) their current educational culture where they are presently studying, and iii) students' major whether it's science or nonscience. Referring to the two dimensions of the study, the sample multicultural population consisted of following five types of students: Type 1 consisted of students who came from a strong uncertainty avoidance and large power distant 
educational cultural background, Type 2 consisted of a strong uncertainty avoidance and a small power distant educational cultural background, Type 3 consisted of a weak uncertainty avoidance and large power distant educational cultural background, and Type 4 consisted of a weak uncertainty avoidance and small power distant educational cultural background and were now studying in a weak uncertainty avoidance and small power distant educational culture. Type 5 comprised students from a weak uncertainty avoidance and small power distance educational cultural background but who were also subject to a degree of strong uncertainty avoidance and/or large power distance educational culture (this was often the case where their parents are from a strong uncertainty avoidance and/or large power distance educational cultural background) studying in a weak uncertainty avoidance and small power distance educational culture.

This study examined students' educational culture in only two dimensions and in the context of Japanese language teaching. The reality of current multicultural students is expected to be more complex, consisting of mixture of students from various types and educational cultures. This type of research may be extended to investigate other nonAnglophone teaching approaches so that language teachers are more informed about different educational culture.

Limitation of the sample is small sample size. However, it was not feasible to increase the size of participants and equalising the ratios as this was the maximum number of students. Despite of these limitations, it is possible to say that the multicultural population of this study is suitable for this study and may be also possible to some conclusions about the specific sample population of this study.

\section{Conclusions}

In the current multicultural learning environment in the British higher educational establishments, language teachers are expected to support and enhance learning experiences of students with whom the teacher do not share the same educational culture. Language teachers are also expected to generate these students' interest and enthusiasm. The results of this study imply that although international students expect to be taught in British way at a British university, the use of educational values from the opposite pole may support some students preferred pedagogy. It is hoped that this study contributes language teachers to enhance some students' learning experiences and generate interests.

\section{Acknowledgement}

I am indebted to Dr. Morgan Herod for his helpful suggestions and comments while writing this paper.

\section{References}

Dimmock, C. (2000). Designing the Learning-Centred School - A Cross-Cultural Perspective. London: Routledge Farmer.

Godwin-Jones, R. (2013). Integrating intercultural competence into language learning through technology. Language Learning \& Technology, 17(2), 1-11.

Hofstede, G., Hofstede, G. J. \& Minkov, M. (2010). Cultures and Organization-Software of the mind (3rd ed.), NY: McGraw-Hill Book Company.

Jin, L. \& Cortazzi, M. (2006). Changing practices in Chinese Cultures of Learning, Language Culture and Curriculum, 19(1), 5-20. doi.: 10.1080/07908310608668751

Lustig, M. W. \& Koester, J. (2010). Intercultural Competence-Interpersonal Communication across Cultures. Boston: Pearson. 